\title{
Erratum to: A Coupled Thermal, Fluid Flow, and Solidification Model for the Processing of Single-Crystal Alloy CMSX-4 Through Scanning Laser Epitaxy for Turbine Engine Hot-Section Component Repair (Part I)
}

\author{
RANADIP ACHARYA, ROHAN BANSAL, JUSTIN J. GAMBONE, and SUMAN DAS
}

DOI: $10.1007 / \mathrm{s} 11663-014-0226-5$

(C) The Minerals, Metals \& Materials Society and ASM International 2014

Erratum to: METALLURGICAL AND MATERIALS

TRANSACTIONS B, 2014

DOI 10.1007/s11663-014-0117-9

EQUATION [8] has been incorrectly typeset in the final version. The first term in the square parentheses is supposed to be a cube root and not a 3 followed by a square root symbol.

An alternate but correct form of Eq. [8] is:

$$
G_{h k l}^{n} / V_{h k l} \geq a\left[\left(\frac{-4 \pi}{3 \ln (1-\varphi)}\right)^{\frac{1}{3}} \sqrt{\frac{N_{0}}{n+1}}\left(1-\frac{\Delta T_{n}^{n+1}}{\Delta T_{t i p}^{n+1}}\right)\right]^{n}
$$

RANADIP ACHARYA, Ph.D. Candidate, is with the George W. Woodruff School of Mechanical Engineering, Georgia Institute of Technology, 801 Ferst Dr., Atlanta, GA 30332-0405. ROHAN BANSAL, formerly a Graduate Student with the George W. Woodruff School of Mechanical Engineering, Georgia Institute of Technology, is now Ph.D. with the Chart Industries, Buffalo, NY. JUSTIN J. GAMBONE, formerly a Graduate Student with the George W. Woodruff School of Mechanical Engineering, Georgia Institute of Technology, is now M.S. with GE Global Research, Niskayuna, NY. SUMAN DAS, Professor and Morris M. Bryan, Jr. Chair, is with the George W. Woodruff School of Mechanical Engineering, Georgia Institute of Technology, and also with the School of Materials Science and Engineering, Georgia Institute of Technology, 771 Ferst Dr. NW, Atlanta, GA 30332-0405. Contact e-mail: sumandas@gatech.edu

The online version of the original article can be found under doi: 10.1007/s11663-014-0117-9.

Article published online October 30, 2014. 